\title{
Patterns of Resource Integration in the Self-Service Approach to Business Analytics
}

\author{
Imad Bani-Hani \\ Lund University \\ imad.bani-hani@ics.lu.se
}

\author{
Olgerta Tona \\ Lund University \\ olgerta.tona@ics.lu.se
}

\author{
Sven Carlsson \\ Lund University \\ sven.carlsson@ics.lu.se
}

\begin{abstract}
The main premise of Self-Service Business Analytics (SSBA) is to make business employees autonomous during the data analytical process. To empower business employees, organizations are decentralizing their analytical capabilities through an SSBA approach. Yet, little is known about how employees integrate resources, such as, among others, personal competencies, environment resources including technology, and to generate insights in SSBA. Based on the empirical data of a major Norwegian online marketplace and drawing on service-dominant logic as an analytical framework, we identify and explain two types of resource integration in an SSBA environment: direct and clustered resource integration (including 1 st tier and 2nd tier) enabled and controlled by three types of institutions. We finally discuss some organizational implications and the meaning of each sub-type of clustered resource integration.
\end{abstract}

\section{Introduction}

Business Analytics (BA) entails the use of data in conjunction with several analytical tools and techniques to drive employees and organizations. By definition, it involves "the extensive use of data, statistical and quantitative analysis, explanatory and predictive models, and fact-based management to lead decisions and actions" [1]. Generating value from business analytics tops the agenda of practitioners and academics [2]. For instance, research shows that top-performing organizations use rigorous data analysis to define future strategies and daily operations [3]. Yet, because of organizational structures and employees' capabilities, highly trained and experienced technical employees (often part of an IT/BI department) face a huge overload of continuous analytical reports requested by other departments. On the other hand, given a lack of general business knowledge, technical employees often are forced to solve business problems beyond their capabilities and understanding. To address these concerns, some organizations have started to decentralize analytics by enabling a self-service environment as a way of engaging employees in data analytics with the minimum possible support of technical employees. Self-Service Business Analytics (SSBA) refers to an approach to BA that "aims to give business users access to selection, analysis, and reporting tools without requiring intervention from IT" [4].

In a typical SSBA environment, the technical department provides data, tools and technologies specifically optimized to lower the operational complexity of processing data into information. As a result, the employees become more autonomous in meeting their own information needs, which in turn enables technical department to focus on more strategic tasks [5]. In such scenario, the value of SSBA is co-created between different actors (which in this case are the business and technical employees). Cocreation occurs when employees' competencies (such as knowledge, experience and technical capabilities) are integrated with the environmental resources enabled and maintained by the staff of the technical department. As such, resource integration is a central activity in an SSBA environment to generate value, that is processing data to generate business insights. SSBA Researchers have addressed several aspects ranging from technological design to user acceptance. For example, authors have attempted to describe SSBA architecture to promote more understanding of what SSBA is from a technical perspective [6]. Others have explored the factors influencing SSBA acceptance [7], user uncertainty during engagement [8] and the gap it creates between a user and an IT department [9]. When it comes to the benefit of SSBA, empirical evidence suggests that SSBA enables organizational agility [5] and employees communication and collaboration [10]. However there is still a need to understand how resources integration occurs in an SSBA environment. As such, this paper aims to explain the process of resource integration and its contribution to a successful value generation given the resources available. From a practical contribution point of view (i.e., managers and IT professionals), this paper clarifies the complexity involved in enabling an SSBA environment.

In such depiction of SSBA environment where value is co-created by different actors through the process of resource integration, this 
paper adopts Service Dominant Logic (SDL) as an analytical lens. SDL implies that value cocreation emerges in an interconnected network of resource integration among actors $[11,12]$.

\section{Service dominant logic}

SDL is a meta-theoretical framework for explaining value creation among configurations of actors through the exchange of resources [13]. The fundamental notion of SDL is that humans apply their competences (personal resources such as knowledge and skills) to support others and equally benefit from others' applied competences within service-for-service exchange [13]. Lusch and Vargo (13) further define service as a process where one uses personal resources (competences) for the benefits of another entity or the entity itself (Vargo and Lusch 2004). SDL claims that in order to create value, actors engage in an interdependent and reciprocally beneficial resource integration and service exchange [13]. Recently, SDL has shifted towards a more dynamic and system oriented view in which value co-creation is managed through shared institutions (norms, symbols, competence) on a broader scale of resource integration and service exchange process [14]. In short, SDL asserts that value is co-created through 1) actors 2) integrating resources and exchanging services controlled and enabled by the 3 ) institutions and institution arrangements within the service ecosystem.

\subsection{Institutions}

Institutions and institutional arrangements are essential during resource integration and service exchange. Institutions encompass actors, norms, rules, beliefs, and general mind-sets that drive actors' actions [15], which are in line with the institutional logic at the individual and organizational level [16]. When actors share the same norms, beliefs, and mind-set, a network effect is created that, in turn, enables a more productive value co-creation [15]. Institutions come in various forms of rules; however Scott (17) has developed a widely accepted categorization built on three main pillars: regulative, normative, and cognitive.

First, the regulative pillar mainly consists of formal rules that enable or constraint actors' behavior in an effort to avoid any kind of formal sanctions. As a result, the actor's behavior is driven to a great extent by self-interest and avoidance of any threatening negative consequences [17].

Second, the normative pillar consists of norms and rules that are defined based on an actor perception of social benefits or constraints.
Those rules are usually formed by the actor as a kind of commitment towards the perceived social expectation and grounded in values of specific industry, groups, and society in general [17]. In short, normative institutions lead to behavior driven by social restrains [18].

Third, the cognitive pillar consists of a set of beliefs originating from actors' perceptions and personal interpretation of their environment [17]. Actors' perceptions and representation of reality as a basis for thinking, feeling and acting lead to a taken-for-granted behavior.

Obviously, the rules, norms, and beliefs originating from the three pillars influence an actor's efforts in accessing, mobilizing, combining, sharing, transforming, integrating resources, and coordinating the resource integration itself [18].

\subsection{Actors}

First, in SDL, all actors fundamentally integrate resources to co-create value [19]. Consequently, without actor engagement, there is no resource integration and no value co-creation. There is no specific definition of what an actor is, however Lusch and Vargo (13) use a more generic construct related to 'social actors', which can be either interpreted as a single human such as an employee in a organization or a collection of humans making the organization itself. For the purpose of this paper, we identify actors by emphasizing the action, interaction, and engagement with technology required for resource integration and value creation in an SSBA environment. Flowing this line of argument, Storbacka, Brodie (20) conceptualize the actor's engagement with resources as "the disposition of actors to engage and engagement activities as activities to integrate resources facilitated by engagement platforms".

In SSBA environment, there are different types of users that act, interact and engage with a data analytical technology. Business users, (often known as casual users) use applications without being aware of the complex analytical processing involved. They have basic technical skills and domain-based expertise. Business analysts, who have extensive analytical skills compared to those of business users, can analyze data, understand how data is organized, retrieve data via ad hoc queries, produce specialized reports, and build what-if scenarios. They often produce information requested by business users. Finally, data scientists who have a strong background in mathematics, statistics, and/or computer science, are able to develop descriptive, predictive, and prescriptive models (perhaps using the discovery platform; e.g., Sandbox), evaluate models, deploy, and test them through controlled 
experiments [21]. The focus of an SSBA approach is to empower the first category of users (i.e., business users, such as field and operational staff, sales-people, business developers, and executives/managers). On the other hand, techno-oriented users are employees whose job description is strongly connected to data analytics, programming skills, intimate knowledge about data sources, and semantic meanings.

\subsection{Resource integration}

Resource integration (RI), a central concept of SDL, is "the process by which customers deploy resources as they undertake bundles of activities that create value directly or that will facilitate subsequent consumption/use from which they derive value" [22, p. 2]. However, the notion of customer-producer dyad in this definition is challenged, and it is further generalized to actor-to-actor networks [23] as discussed in the previous section. Resource integration happens for two main reasons: first, to generate value or usefulness when resources obtained by an actor are combined or bundled with other resources [24], and second, to encourage innovation through recombination of existing resources [25]. Both reasons require that for a certain activity to generate usefulness, combination or recombination of resources should take place. In that sense, the presence and availability of resources does not imply resource integration per se [13] but rather they can be potential or passive resources. In the same line of thought, once the resourceness (capabilities) of the resource is acted upon or used by an actor's competencies (such as knowledge and skills) it becomes actual resource and its state changes to active [26]. The notion of resource integration in SDL comprehensively takes into account the vast and intrinsic network involved in value creation [23, p.49]. This network is not only a network of resources but also of actors, it is rather a continuous process and connection among all the actors. In an SSBA environment, different resources are available to facilitate and enable user independence in insight generation. Resources such as technology, processes, actors' support (business and techno-oriented users) potentially are the basis for such networks.

Resource integration occurs in the context of a service system in which the actor employs personal competencies, intentions and motivations influenced by the institutions. The actions taken by the actor also influence existing institutions. In other words, institutions influence actors' behavior and vice versa, actors influence institutions through their behaviors.

\section{Method}

This paper adopts a single case study design [27]. Through qualitative interviews including field visits and secondary data in form of documents, we provide rich descriptions [28] and insights to investigate how resource integration occurs when business users interact with tools, applications, and other techno-oriented employees to solve analytical tasks. To meet the aim of this study, we chose an organization that fulfilled two main requirements: (a) data intensive organization, and (b) an enabled SSBA environment for its employees.

\subsection{Case}

Finn.no, a top digital marketplace in Norway, met both of our selection criteria. Parties, such as buyers, sellers, and market intermediaries use Finn.no's digital platform and services to carry out business transactions and activities.

Finn.no has become a central data repository where agencies (private and public) constantly send requests that consist of various statistical analysis and ad hoc reports. In addition, high profile sellers are requesting reports from departments of marketing and sales about their advertisement reach and thereby investments value. Due to an increase in ad hoc requests from external customers and internal employees, in 2010, Finn.no management decided to invest to become a more data-driven organization, where employees could easily access and analyze business data to perform their daily tasks more independently. For this purpose, the organization adopted an SSBA approach, which could (hopefully) augment employees' capabilities to handle not only external customers' requests in time, but also their personal needs for timely information.

\subsection{Data collection and Analysis}

There are two sources of evidence in this study: semi-structured interviews including field visits and organizational document containing surveys with employees and internal documents such as data sources, tools and techniques for data analysis. Thirteen semi-structured interviews (15 hours were recorded, transcribed, and loaded into NVIVO11 with the consent of the interviewees) took place at Finn.no between February and May 2016, in Oslo, Norway. We have also seized the opportunity to observe and take notes on how the current employees use the SSBA tools.

The interview guide was developed based on SDL's main components and questions in relation to resource integration in SSBA (e.g. 
business decisions based on the data we have available and if some claims are not true we try to gather what's necessary [data] to get the facts and back up what you say? (business user).

Obviously, regulative institutions had an important role to play when those small groups were created. This is a good example when organization falls behind in promoting a strategy or vision; the actual need of employees precedes organizational actions. Consequently, the organization took many initiatives to support such movement by including 'data-driven' as a main pillar in the organization vision. The management also started to provide a more selfservice and data driven environment by introducing dynamic data metrics of the organization activities visualized on big screens in most of the departments as observed at Finn premise. The have also democratized data through the organization by providing access to existing data model already developed by employees and build new ones.

In other words Finn realized that they should nurture needed institutions, such as data driven and fact-based decision-making. "The key thing that we are doing is trying to make existing structured data available, such that more users within Finn can retrieve data so that they can analyze the data themselves..."(TOE)

In an effort to make data a part of everyday decisions through the organization, the management has created initiatives such as awareness seminar, trainings, and success stories related to the data driven mind-set. They have also mentioned that they need to have data embedded in any decisions they make and be part of their daily routines by metaphorically referring to the use of data as 'instinct'. "What we essentially said in our organization is that we want data to be a part of our instinct." (CFO), "Our organization strategy has six areas, one of the six areas; data in our spine. It was one of the focus areas and we some activities [seminars and workshops] related to that." (business users).

Some employees perceive these transformations in the organization as 'core changes' that enable them to work independently with data. The initiatives from the organizational management have affected their cognitive institutions such as the perceptions and representation of the surrounding reality. "I think the change is in the way that I used to do things, the change is that I look at what I am supposed to do" (business user), "making kind of the best decision possible and try really to be data driven and challenge others being data driven at my unit and also we work a lot cross-rational so trying to get them to be fact-based and data driven, but it's kind of a transformation I would say." (business users), "I would say it's like we have this special culture. It's kind of a bit intangible I would say, but it's like how I should say this... is related to our standardized processes" (business users).

\subsection{Actors}

Based on our finding, four types of actors are identified. First, business user are the actors who initiate the process of data analytics to either address a problem/opportunity or answer a question. Second, business support are those actors who provide support for the business user in case they need an advice regarding a business situation. Third, $1^{\text {st }}$ tier TOE are the actors who provide technical support for business users and considered the first point of interaction with the technical department. Fourth, $2^{\text {nd }}$ tier TOE are the actors who support $1^{\text {st }}$ tier of TOE in case a support could not be provided by the latter.

\subsection{Resource integration}

From a SDL perspective, operant and operand are recognized as two types of resources in a service system. The operand resources are defined as "resources on which an operation or act is performed to produce an effect" [31, p.2] (e.g., tools and data analytics platform), whereas the operant resources are the actual human capital that acts on the operand resources and are characterized by intangibility (e.g., knowledge and skills [31, 32].

Based on the SDL resource categorization, in an SSBA environment we identity three main categories of resources that are exchanged during resource integration: (1) Environment Resources (ER), such as tools and applications that support data access, manipulation and processing, documents and many others (operand resources), (2) an actor's Personal Competencies denoted as (PC), such as technical skills, business knowledge, and experience (operant resources); and (3) other actors' personal competencies when support is needed denoted as Other Personal Competencies (OPC) (operant resource). These resources are enacted through two main resource integration patterns, which is direct and clustered resource integration.

\subsubsection{Direct Resource Integration}

In direct resource integration, a single actor enacts appropriate resources to generate insights. In this type of integration, a business employee has the capability to independently engage in the data collection process, data preparation, data analysis, data representation (visualizations), and interpretation of the results to generate insights (i.e., without the support of TOE). This process is realised by recalling the actor's competencies, 
such as business knowledge and relevant technical skills (see Table 1 capabilities) to engage mainly with ER available in the SSBA environment. Often a business user engages through the whole processes of data analyses to generate insights by interacting with ER only. A business user stated: "I organize my sales data in a specific format [PC, ER] to see if I am missing commission" (business user), "I sit and play with data [ER] and looking for some answers to solve questions and when I think have sort of found something I usually share it with one of the guys sitting next to me"'(business user)

In such case it is clear that the user possess the required competencies to assume independence and interact with several environment resources such as data models, analytical tools and business segmentation. "I use Tableau [ER] and build reports based on customer data [ER] and business segments [ER] to show me how many impressions [i.e., views] per search on our platform..." (business user), "I use self-service tools [ER] to see how many save ads and how many have saved searches on this topic." (business user). In certain cases the task at hand may be complex and to assume independence business users should own somehow advanced personal competences such as data manipulation, data integration and statistical analysis (please refer to Table 1) to design specific reports in specific formats. "I have good technical experience [PC] in Tableau [ER] so I have created some customer reports based on my business understanding [PC] [and placed them] on my desktop using the desktop version of Tableau [ER] ... I can easily extract very quickly all the data on my machine and all the tables and formatting the way I want." (business user)

The availability or resources and access to data are important but not enough to assume independence. A user should have the ability to orchestrate tools, data, and analytical processes in line with the personal competences (see Table 1 for detailed needed competencies) to answer either a problem or an opportunity. "So I need to go and make an extract from Tableau [ER] and an extract from CRM [ER] system and then match that data to get the industry and size of the company $[P C]$... so I pull data from different sources and put them into Excel [ER] ... it is easier in Excel.. I know Excel is not the best BI visualization tool but it's good for some stuff." (business user), "Excel, Adobe, Tableau [ER] and then I sometimes use [PC] different tools [ER] to scrape website [data] in order to get data structures of competitors... I use Google Analytics as well. [ER]” (business user)

\subsubsection{Clustered Resource Integration}

In the clustered Resource integration, $a$ network of actors enacts appropriate resources to generate insights. Due to lack of necessary business knowledge or skills to perform a task, a business user may require some assistance from $1^{\text {st }}$ tier TOE (i.e., enact other personal competences) to complete a task. They may also need assistance from business support employees to understand a certain business situation, which again requires enacting other personal competences. Furthermore, a network of actors collaborating together and enacting ER is noticeable. The more OPCs are enacted, the bigger the network becomes.

\section{- 1st-tier}

The $1^{\text {st }}$ tier is a resource integration pattern where only one cluster is created before developing the desired insight. Despite the enactment of OPC (technical or business), the initial actors still lead and control the insight generation. In other words, business employees deliver the final results after they have enacted PCs, ERs, and OPCs to perform a task. In contrast to the previous resource integration type - where support is not needed-, business employees are not independent.

Concerning the nature of support and assistance of $1^{\text {st }}$ tier TOE provide. "One would be just getting help extracting or manipulating [OPC] the data or just getting the tie (connection) to do it." (business user)," I personally want to include them more and not just extracting the data and putting it up on the dashboard." (business user), "Sometimes I need to go many years back in time [in the data] so it gets more complicated. I need to get help from the IT/BI department [OPC] to get some data directly from the data base and provide me an answer to my questions." (business user)

The need for technical assistance is mainly caused by a lack of PC such as the competencies needed to identify data sources and assess the quality of data and many other related to data gathering (see Table 1). "There are tremendous amount of data base connections that have similar names that I don't understand [PC] so these differences in the connections and so forth and obviously it's frustrating to build my own advanced thing which takes a lot of times." business user, "but if it's more advanced I go downstairs [to the IT/BI department], scratch on the door and ask for help. "(business user)

Furthermore, a lack of knowledge on how to prepare data once a data source is identified and the uses of several data sources also drive business users to ask for support. Table 1 shows the different activities related to data preparation. Some of them are less complex and some need 
special skills. "Its tough for me to create a whole new report because I don't really know [PC] what data have good quality and clean. I mean what data sources have good and useful data and which one have dummy data", "I include them [techno-oriented employees] Not just relieving [setting up] the dashboard or the data, but also including them in problem solving. "(business user)

Users also require assistance in less complicated tasks either to confirm what they did or ask about a specific issue they have. "...They come to us more to verify that they have built a valid representation of the data. So, they want to know if they used the right fields, if they have added the right filters" (1st tier TOE) "if I do more complex analysis; I try to go back and ask them what's wrong with what I have done so that they could pin point or try to look at my stuff and see if I have done anything that doesn't make sense" (business user)

The variability of the employee's business experience and knowledge requires business support to be available especially in complex situations. Formulating a problem and developing a question involves a deep and valid understanding of the information gathered in connection to the business involved. "I think it's also to get the understanding of it's more than just insights; what's happening on the business side, what's happening on the competitive side like getting more the holistic perspective of the market place?" (business user), "Are there any products that we sell to our current people and the pricing manager in my department and there I really challenge him to kind of understand what's going on there and use that data" (business user), "we try to work together as a team and solve these tasks together and we also have other departments that we can involve. We have..." (business user).

\section{- 2nd-tier}

The $2^{\text {nd }}$ tier is a resource integration pattern where more than one cluster is created before developing the desired insight. In some cases, the data available for a business employee is not complete and new data is required. In that case, the business employee contacts the $1^{\text {st }}$ tier techno-oriented employee. If the data is available in the data warehouse then they contact a more specialized within the department ( $2^{\text {nd }}$ tier TOE) to load it into the data model and make it available for others. "If people have requests for additional information they want into the data model, we try to provide it based on priorities. This process is rather complicated unless it's something that is already in the staging process and I mean in the data warehouse [ER]. So, if it is not, then we take over the report development, consult other departments and then we provide the answers directly." (1 $1^{\text {st }}$ tier TOE).

However, if the data is not available in the data warehouse, the $1^{\text {st }}$ tier techno-oriented employees contact more specialized employees from other technical department. "...the first step in, for instance, in getting a new field into the self-service [ER] tool that would be to have a change ticket with the data warehousing team [OPC] right. So the data warehousing team would then transfer data from any source system and then amend it to a table depending on if it's a dimensional or fact that would fit into all pre built model. So as soon as they've made that field available within the data warehouse either me or $X$ can go in and update [PC] our the self-service [OPC] data model" (1 ${ }^{\text {st }}$ TOE).

\section{Discussion}

SSBA is an approach to data analytics that basically enables its users to experience a higher degree of independence while exploring and exploiting data in the process of attending to a business need $[5,33]$. Yet, this process depends on institutions, resources, and actors that are active in a SSBA environment. The findings of this study, in terms of insight generation, are in line with SDL in that the network structure of the interplay between actors and resources is enabled and controlled by institutions to co-create value $[14,34]$. The focus of this study is on resource integration shaped by institutions in an SSBA environment once the process of insight generation is initiated.

During resource integration, different actors collaborate together to co-create the desired value. Solving an analytical task often requires a business user to collaborate with others (i.e., as per their corresponding job descriptions). Because institutions shape actors behavior (and vice versa) [18], they are also expected to coordinate resource integration during a collaborative work. This is in particular important when conflicts emerge as a result of individuals or organizations who act according to their self-interest [35]. In this context the cluster become a silo of resource integrating through collaboration and cooperation. Once this cluster is institutionalized, it becomes a source for insight generation, hence delivering the premise of SSBA.

While institutions describe and conceptualize user behavior in an SSBA environment, resource integration depicts the actual engagement of an actor with the resources available by enacting and interacting with data, technology, other actors and resources to address a business need. Based on our findings, two types of resource integration occur, namely the direct and the 
clustered resources integration. In the direct resource integration, the enactment of resources occurs in a linear fashion. A business employee recalls $\mathrm{PC}$ to interact with ER1, ER2 ... ERn until data insight is generated (see Figure 1A). There are no specific rules on what and when certain resources are enacted because it mainly depends on an employee's PC and how institutions affect his behavior. It implies that collaboration is absent in this case and the only coordinating institutions are those belonging to the actor and established within the organization. By linear we mean that no OPCs are enacted in such interaction and the driver is only one actor and own PC, which prevent the formation of a cluster, as we see next in the clustered resource integration. This scenario does not imply the absence of value co-creation. In fact, the SSBA environment in which this scenario and the next one occurs is fully maintained and managed by techno-oriented actors.

In the clustered resource integration, due to the fact that actor's PC entails technical skills, experience, and business knowledge, the probability of requiring assistance in certain tasks cannot be neglected. In such case, the enactment of resources does not follow a linear fashion but a rather nested one. For example, a business employee enacts PC to interact with ER1 then ER2 and then maybe followed by OPC1 then OPC2 ... OPCn, ERn..There is no specific path whether ER or OPC comes first, however every time an OPC is enacted a cluster is created. The reason for the emergence of such cluster is that each OPC represents the competencies of other employees in an SSBA environment or what we refer to as support actors. Those actors in their turn can enact ER to provide assistance, hence creating a cluster (see Figure 1B). Based on our findings, two types of cluster can emerge, that are $1^{\text {st }}$ tier cluster and $2^{\text {nd }}$ tier cluster. In both types of clusters, institutions are important as they safe guard the resource integrations process during collaboration. The $1^{\text {st }}$ tier cluster constitutes the direct support that a business user provides in case the initial actor lacks specific business understanding or the techno-oriented user provides support in answering a technical question. In both cases, support is provided directly without the need to include more specialized people. This scenario is a direct result of miss alignment between an actor's PC and ER during resource integration. The $2^{\text {nd }}$ tier cluster (see Figure 1C), emerges when $1^{\text {st }}$ tier cluster cannot provide the needed support and more specialized people are recruited. In such scenario, the support actor in the 1st tier cluster creates a cluster on his own. Both scenarios are an empirical proof of the network nature of resource integration described in the process of value co-creation described by SDL $[15,36]$.

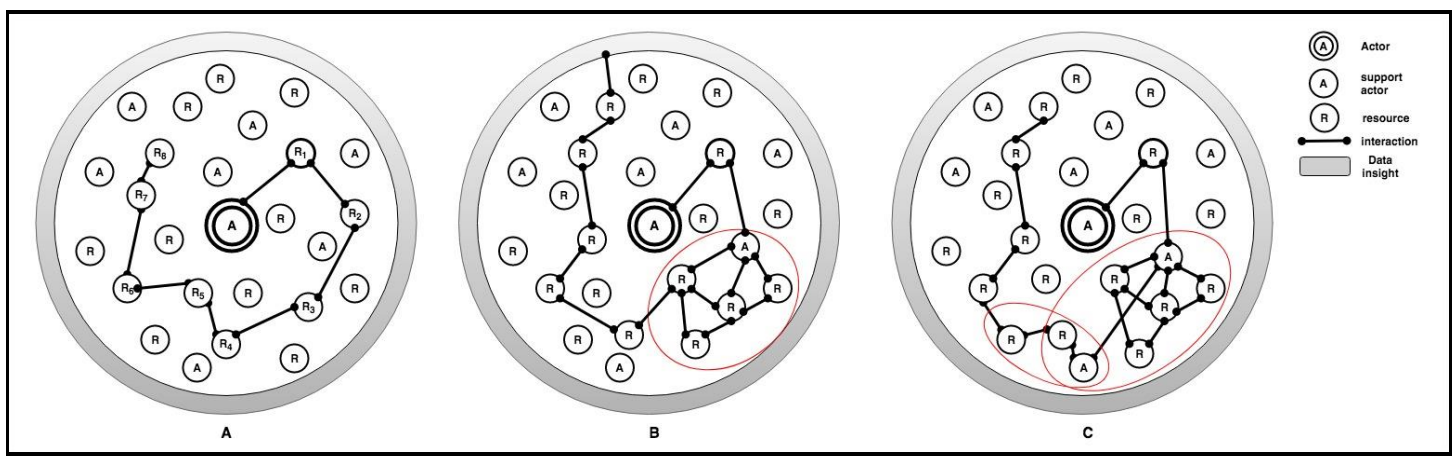

Figure 1: Patterns of resource integration

From an organizational perspective, in direct resource integration, employees' work efficiency is enhanced primarily because they will feel in control of their work and secondly, the time it takes to communicate with other employees will be significantly reduced. Moreover, data analytics decentralization [37] can be achieved because there will be more autonomous users and fact-based decisions may be infused across levels of an organization [38, 39]. Furthermore, direct resource integration aids in curtailing the time needed for supporting actors like techno-oriented employees to handle daily ad-hoc data analytical requests, in line with other recent research that indicates that IT/BI resources should be used more efficiently and effectively on strategic projects [40, 41].

In term of clustered resource integration, we have described two types of clusters, namely $1^{\text {st }}$ tier and $2^{\text {nd }}$ tier. In the $1^{\text {st }}$ tier, business users competencies are not fully aligned with the resources available, mainly because of the lack of certain skills (business of technical) and capabilities, which pushes them to require support (business or technical). However, both cases institutions coordinate the process of data analytics especially when several actors are involved and collaboration is a must. In that case organizations can act by offering training programs for employees to obtain more solid 
technical knowledge and enhance their competencies. Second, organizations can also create 'mentorship' programs where small groups of business users can work for a specific time with techno-oriented users. We believe that this can (hopefully) increase business users' self-confidence and abilities on completing an analytical task. In the 2nd tier, more specialized support is needed due to the fact that certain resources are missing or ill configured in the SSBA environment which limits its potential value. As such this type of clusters affect directly the SSBA environment and unveil hidden issues that may affect many business users.

Table 2: Summary of resource integration patterns

\begin{tabular}{|l|l|l|}
\hline $\begin{array}{l}\text { Resource } \\
\text { integration pattern }\end{array}$ & Description - SDL view & Implication - meaning \\
\hline 0-tier (direct) & $\begin{array}{l}\text { The actor's institution, personal } \\
\text { competencies (knowledge and } \\
\text { skills) and SSBA environment } \\
\text { (technology and data provided) } \\
\text { are aligned and enable a self- } \\
\text { governing value co-creation. }\end{array}$ & $\begin{array}{l}\text { The ideal scenario where the user } \\
\text { competencies are fully aligned with the } \\
\text { SSBA environment resources, which } \\
\text { results in full autonomy and } \\
\text { independence. }\end{array}$ \\
\hline $\begin{array}{l}\text { 1-tier (1 cluster) } \\
\text { personal competencies } \\
\text { (knowledge and skills) fall } \\
\text { behind leading to the creation of } \\
\text { a network. }\end{array}$ & $\begin{array}{l}\text { There is a miss-alignment between the } \\
\text { users competencies and the other } \\
\text { resources provided in the SSBA } \\
\text { environment. Organizations should } \\
\text { provide training sessions and mentorship } \\
\text { programs. }\end{array}$ \\
\hline 2-tier (2 clusters) & $\begin{array}{l}\text { The SSBA environment lacks } \\
\text { certain resources and requires } \\
\text { improvements. It prevents actor } \\
\text { from successfully integrating } \\
\text { resources. }\end{array}$ & $\begin{array}{l}\text { The SSBA environment is still immature } \\
\text { and prevents users from having a } \\
\text { successful insight generation. } \\
\text { Organization could re-evaluate the SSBA } \\
\text { environment and unveil potential issues. }\end{array}$ \\
\hline
\end{tabular}

Our research contributions need to be considered in light of this study's limitations. First, this study does not explore the process of how the interaction between the different elements of an SSBA environment occurs (actorresource, resource-resource, resource-actor and actor-actor), but rather uses as grounds to study the arrangement of ER, PC and OPC when integrating resources in an SSBA environment. Still, we believe that this is an opportunity for some new avenue of research in order to better understand the mechanisms that may exist during the process of resource integration. Second, future studies could also investigate a SSBA from a decision-making perspective as a final outcome of the data analytics process. Finally, It would be also interesting to investigate the role of sense making while interacting with the SSBA environment resources.

\section{Conclusion}

This paper investigate resources integration patterns in a self-service approach to data analytics enabled by the SSBA environment through the lens of SDL [13]. By portraying SSBA environment as a service environment within an organization, we have discussed how SSBA environment nurture regulative, normative and cognitive institutions. We have also identified two major types of resource integration and described their patters in such environment. Finally, we describe each pattern in relation to SDL and its meaning from an organizational perspective.

\section{References}

[1] Davenport TH, Harris JG. Competing on analytics: The new science of winning: Harvard Business Press; 2007.

[2] Mithas S, Lee MR, Earley S, Murugesan S, Djavanshir R. Leveraging Big Data and Business Analytics [Guest editors' introduction]. IT professional. 2013;15(6):18-20.

[3] LaValle S, Lesser E, Shockley R, Hopkins MS, Kruschwitz N. Big data, analytics and the path from insights to value. MIT sloan management review. 2011;52(2):21.

[4] Schuff D, Corral K, Louis RDS, Schymik G. Enabling self-service BI: A methodology and a case study for a model management warehouse. Information Systems Frontiers. 2016:1-14.

[5] Bani Hani I, Deniz S, Carlsson S, editors. Enabling Organizational Agility Through Self-Service Business Intelligence: the case of a digital marketplace. The Pacific Asia Conference on Information Systems (PACIS) 2017; 2017.

[6] Passlick J, Lebek B, Breitner MH. A self-service supporting business intelligence and big data analytics architecture. 2017. 
[7] Daradkeh M, Moh'd Al-Dwairi R. Self-Service Business Intelligence Adoption in Business Enterprises: The Effects of Information Quality, System Quality, and Analysis Quality. Operations and Service Management: Concepts, Methodologies, Tools, and Applications: IGI Global; 2018. p. 1096118.

[8] Weiler S, Matt C, Hess T, editors. Understanding User Uncertainty during the Implementation of SelfService Business Intelligence: A Thematic Analysis. Proceedings of the 52nd Hawaii International Conference on System Sciences; 2019.

[9] Haka E, Haliti R. The effects of Self Service Business Intelligence in the gap between Business users and IT. 2018.

[10] Pickering C, Gupta M, editors. Self service business intelligence (SSBI) for employee communications and collaboration (ECC).

Collaboration Technologies and Systems (CTS), 2015 International Conference on; 2015: IEEE. [11] Vargo SL, Lusch RF. Service-dominant logic: continuing the evolution. Journal of the Academy of marketing Science. 2008;36(1):1-10.

[12] Vargo SL, Maglio PP, Akaka MA. On value and value co-creation: A service systems and service logic perspective. European management journal.

\section{8;26(3):145-52.}

[13] Lusch RF, Vargo SL. Service-dominant logic: Premises, perspectives, possibilities: Cambridge University Press; 2014.

[14] Vargo SL, Lusch RF. Service-dominant logic 2025. International Journal of Research in Marketing. 2017;34(1):46-67.

[15] Vargo SL, Lusch RF. Institutions and axioms: an extension and update of service-dominant logic. Journal of the Academy of Marketing Science. 2016;44(1):5-23.

[16] Thornton PH, Ocasio W. Institutional logics. The Sage handbook of organizational institutionalism. 2008;840:99-128.

[17] Scott WR. Institutions and organizations: Ideas, interests, and identities: Sage Publications; 2013.

[18] Edvardsson B, Kleinaltenkamp M, Tronvoll B, McHugh P, Windahl C. Institutional logics matter when coordinating resource integration. Marketing Theory. 2014;14(3):291-309.

[19] Wieland H, Koskela-Huotari K, Vargo SL.

Extending actor participation in value creation: an institutional view. Journal of Strategic Marketing. 2016;24(3-4):210-26.

[20] Storbacka K, Brodie RJ, Böhmann T, Maglio PP, Nenonen S. Actor engagement as a microfoundation for value co-creation. Journal of Business Research. 2016;69(8):3008-17.

[21] Phillips-Wren G, Hoskisson A. An analytical journey towards big data. Journal of Decision Systems. 2015;24(1):87.

[22] Hibbert S, Winklhofer H, Temerak MS.

Customers as resource integrators: toward a model of customer learning. Journal of Service Research. 2012:1094670512442805.
[23] Vargo SL, Lusch RF. Service-dominant logic 2025. International Journal of Research in Marketing. 2016.

[24] Lusch RF, Nambisan S. Service Innovation: A Service-Dominant Logic Perspective. Mis Quarterly. 2015;39(1):155-75.

[25] Arthur WB. The nature of technology: What it is and how it evolves: Simon and Schuster; 2009.

[26] Peters LD. Heteropathic versus homopathic resource integration and value co-creation in service ecosystems. Journal of Business Research. 2016;69(8):2999-3007.

[27] Hayes SC, Barlow DH, Nelson-Gray RO. The scientist practitioner: Research and accountability in the age of managed care: Allyn \& Bacon; 1999.

[28] Schultze U, Avital M. Designing interviews to generate rich data for information systems research. Information and Organization. 2011;21(1):1-16.

[29] Miles MB, Huberman AM, Saldana J. Qualitative data analysis: A methods sourcebook. 3rd. Thousand Oaks, CA: Sage; 2014.

[30] Miles MB, Huberman AM. Qualitative data analysis: An expanded sourcebook: Sage; 1994. [31] Vargo SL, Lusch RF. Evolving to a new dominant logic for marketing. Journal of marketing. 2004;68(1):1-17.

[32] Arnould EJ, Price LL, Malshe A. Toward a cultural resource-based theory of the customer. The service-dominant logic of marketing: Dialog, debate and directions. 2006:320-33.

[33] Bani-Hani I, Tona O, Carlsson S. From an information consumer to an information author: a new approach to business intelligence. Journal of Organizational Computing and Electronic Commerce. 2018;28(2):157-71.

[34] Akaka MA, Vargo SL. Extending the context of service: from encounters to ecosystems. Journal of Services Marketing. 2015;29(6/7):453-62.

[35] Haase M, Kleinaltenkamp M. Property rights design and market process: Implications for market theory, marketing theory, and SD Logic. Journal of Macromarketing. 2011;31(2):148-59.

[36] Overkamp T, Johan B, Rodrigues V, Arvola M, Holmlid S, editors. Resource integration as a perspective on value in interaction design. British HCI 2018; 2018: BCS Learning and Development Ltd.

[37] Grossman RL, Siegel KP. Organizational models for big data and analytics. 2014.

[38] Davenport TH. Competing on analytics. harvard business review. 2006;84(1):98.

[39] Davenport TH, Harris JG, Morison R. Analytics at work: Smarter decisions, better results: Harvard Business Press; 2010.

[40] Chen H-M, Schütz R, Kazman R, Matthes F. How Lufthansa Capitalized on Big Data for Business Model Renovation. MIS Quarterly Executive.

2017;16(1).

[41] Peppard J, Ward J. The strategic management of information systems: Building a digital strategy: John Wiley \& Sons; 2016. 